\title{
Single-port Laparoscopic Liver Resection in Patients with Previous Abdominal Surgeries: Is it a Feasible Approach?
}

\author{
Miryam Cantos-Pallares ${ }^{1}$, Jose Mir-Labrador ${ }^{2}$, Carlos Rafael Redondo-Cano ${ }^{1}$, Ruth Nuñez-Ronda ${ }^{1}$, Enrique \\ Artigues-Sanchez de Rojas ${ }^{1}$ and Ricardo Fabra-Ramis ${ }^{1}$ \\ ${ }^{1}$ Department of Hepatobiliary Pancreatic and Liver Surgery, General University Hospital, Valencia, Spain \\ ${ }^{2}$ Advanced Laparoscopic Hepatic Surgery Unit, General University Hospital, Valencia, Spain
}

\begin{abstract}
Single-port laparoscopic liver surgery has become an attractive procedure for many surgeons in order to decrease surgical aggression and the complications related to laparoscopic ports. The aim of this study is to assess the feasibility and efficacy of single-port laparoscopic liver resections in patients with previous upper or lower abdominal surgery. A series of ten patients with history of previous abdominal surgery who underwent single-port laparoscopic surgery for liver metastases, primary liver cancer or benign hepatic tumor, is being presented here. Several clinical and operative parameters were reviewed from a historical database of laparoscopic hepatectomy.
\end{abstract}

Key Words: Laparoscopic liver surgery, Single-port, Previous abdominal surgeries.

How to cite this article: Pallares MC, Labrador JM, Cano CRR, Ronda RN, Ramis RF. Single-port Laparoscopic Liver Resection in Patients with Previous Abdominal Surgeries: Is it a Feasible Approach?. J Coll Physicians Surg Pak 2022; 32(01):96-98.

\section{INTRODUCTION}

Laparoscopic surgery is evolving towards the development of less invasive techniques, obtaining the same functional and oncological results as open surgery. ${ }^{1}$ The current trend is to reduce the number and size of surgical incisions looking for less aggressiveness, decreasing the complications related to the surgical site and improving a quicker recovery of the patients. Single-port laparoscopic (SPL) resection has provided an intermediate point into the development of minimally invasive surgery with the intention of causing less aggression to the abdominal wall. ${ }^{2}$ There are no relevant articles about SPL hepatic resections with previous abdominal surgery.

The aim of this paper is to show our experience in single-port laparoscopic liver resections in patients with history of previous abdominal surgery.

\section{METHODOLOGY}

Consecutive patients, who underwent SPL surgery for liver metastases, primary liver cancer or benign hepatic tumor between March 2017 and July 2020 in the Advanced Hepatic Surgery Unit of the Department of Hepatobiliary Pancreatic and Liver Surgery in General University Hospital of Valencia, were reviewed froma historical data-base of laparoscopic hepatectomy.

Correspondence to: Dr. Miryam Cantos Pallares, Department of Hepatobiliary Pancreatic and Liver Surgery, General University Hospital, Valencia, Spain

E-mail: micanpa@hotmail.com

Received: November 10, 2020; Revised: August 31, 2021; Accepted: October 15, 2021
DOI: https://doi.org/10.29271/jcpsp.2022.01.96

Major hepatectomies or limited hepatectomies in patients with only one previous surgery were excluded because they were performed by the conventional laparoscopic approach. In general, SPL surgery was indicated for hepatic tumours in patients with at least 2 or more previous surgeries in the supramesocolic compartment, in whom an important adherent component was suspected that could hinder the traditional laparoscopic access.

In all the cases, an incision of 3 to $5 \mathrm{~cm}$ was made, taking advantage of the scar of previous laparotomies, through which Alexis ${ }^{\circledR}$ retractor was placed as a wall separator. Next, number-8 surgical glove of Biogel ${ }^{\circledR}$ was attached to conform a hybrid multiport (Figure 1). Laparoscopic hepatectomy was then performed. Demographics, surgical duration, blood loss, hospital stay and postoperative complications were noted and described as frequencies, percentages or mean values with range.

\section{RESULTS}

Between March 2017 and July 2020, nine patients ( 3 women and 7 men) underwent SLP liver resection with a median age of 71 (58.5-80) years. One of the cases needed liver resection twice due to tumor recurrence, using in both of the cases SPL surgery, so the total number of procedures was 10 (80\% liver metastasis of colorectal adenocarcinoma, 10\% hepatocellular carcinoma and $10 \%$ recurrent hydatid cyst). Only 2 procedures (20\%) could not be completed by SPL, being necessary the conversion to open surgery. The median surgical time was 252 (172-300) minutes, and mean estimated blood loss was $200.5 \mathrm{ml}$ (129.8-420.3). No patient needed blood transfusion in the postoperative period. 
Table I: Operative parameters. LH limited hepatectomy; HS hepatic segmentectomy.

\begin{tabular}{|c|c|c|c|c|c|c|c|c|}
\hline Case & $\begin{array}{c}\text { Surgical } \\
\text { technique }\end{array}$ & Location & Iwate classification ${ }^{4}$ & Surgical time (min) & 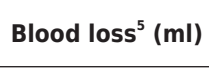 & $\begin{array}{c}\text { Morbidity } \\
\left(\text { Clavien-Dindo }^{6}\right)\end{array}$ & $\begin{array}{c}\text { Hospital stay } \\
\text { (days) }\end{array}$ & $\begin{array}{l}\text { Tumor, } \\
\text { n (mm)* }\end{array}$ \\
\hline 1 & $\mathrm{LH}$ & S5-8 & Intermediate (5) & 375 & 665.1 & II & 7 & $1(25)$ \\
\hline 2 & $\mathrm{LH}$ & S6, S7 & Intermediate (5) & 300 & 464.9 & 1 & 2 & $3(10,10,7)$ \\
\hline 3 & Biopsy & Diaphragm & Low (0) & 150 & 166.9 & I & 2 & $1(8)$ \\
\hline 4 & Fenestration & S4b, S5, S8 & Low (0) & 195 & 221.7 & I & 3 & $1(90)$ \\
\hline 5 & $\mathrm{LH}$ & S5, S7 & Advanced (7) & 300 & 321.7 & I & 3 & $2(50,60)$ \\
\hline 6 & $\mathrm{LH}$ & S4a & Intermediate (5) & 300 & 139.8 & I & 4 & $1(25)$ \\
\hline 7 & $\mathrm{LH}$ & S8 & Intermediate (5) & 180 & 405.5 & I & 4 & $1(20)$ \\
\hline 8 & $\mathrm{LH}$ & S3 & Low (2) & 105 & 100.3 & I & 2 & $1(40)$ \\
\hline 9 & $\mathrm{LH}$ & $\mathrm{S} 2$ & Low (2) & 295 & 77.2 & 1 & 2 & $1(18)$ \\
\hline 10 & $\mathrm{LH}$ & $54 b$ & Low (3) & 210 & 179.4 & I & 2 & $1(22)$ \\
\hline
\end{tabular}

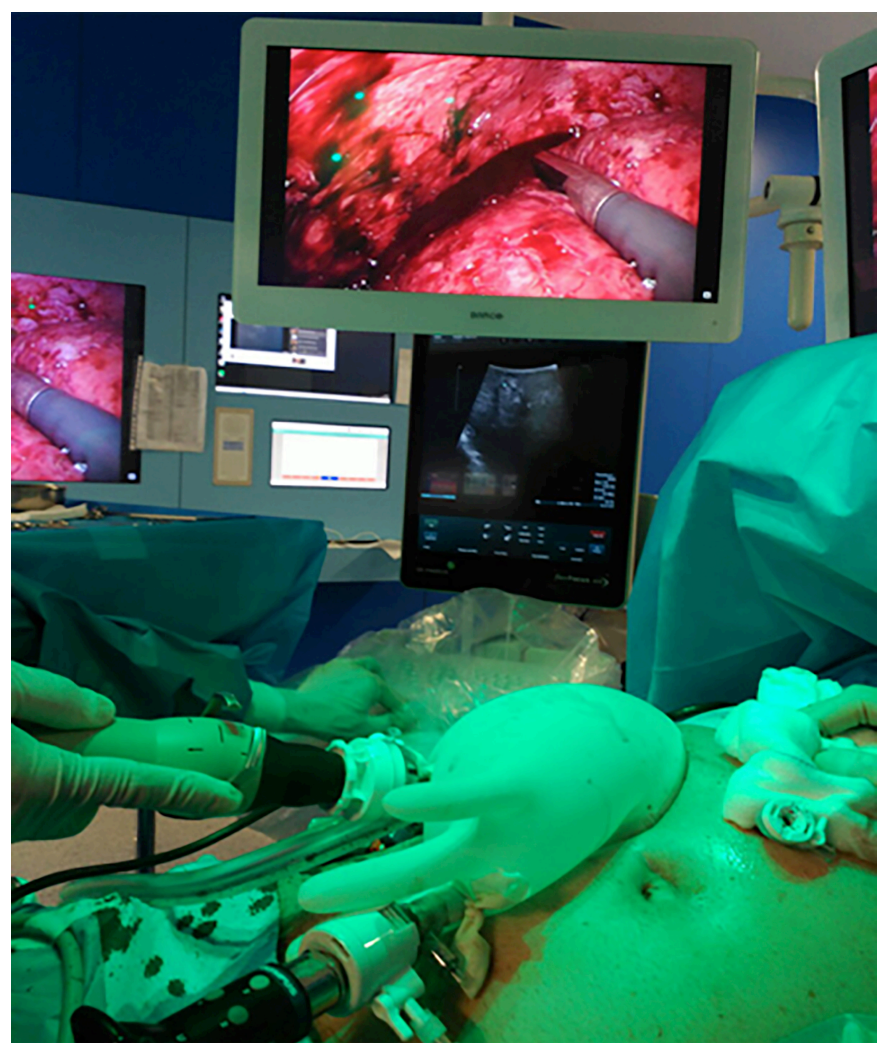

Figure 1: Hybrid multi-port marked with a surgical glove.

The mean hospital stay after surgery was 2.5 days (2-4). No complications related to surgical technique were observed in any of the 10 procedures. One patient developed a bile leakage that was managed with the intraoperative perihepatic drain and was resolved completely two weeks after surgery. No patient developed postoperative severe morbidity (10\% grade II and $90 \%$ grade I, based on the Clavien-Dindo classification). During a mean 8.7 (3-13.3) months follow-up period, no short- or long-term wound-site complications were identified (Table I).

\section{DISCUSSION}

Laparoscopic liver surgery was first introduced in $1992 .{ }^{3}$ The technical difficulty in bleed control and risk of serious complications, such as gas embolism, were the main reasons for the delay of the general adoption of this technique. Since then, its use has spread slowly and constantly parallel with the development of surgical skills and devices. At the consensus meeting celebrated in Louisville, it was said for the first time with scientific evidence, that laparoscopic liver resection performed by surgeons with experience in advanced hepatobiliary surgery and laparoscopic surgery was a safe and effective technique equivalent to open surgery in terms of morbidity. ${ }^{4}$ Compared to open surgery, laparoscopic hepatic resection leads to less intraoperative blood loss, less postoperative pain, shorter hospital stay, faster recovery, better aesthetics and less comorbidity with similar oncological results.,

The current trend is to reduce the number and size of incisions in order to decrease surgical aggression and the risk of complications related to laparoscopic ports (infection, incisional hernia, tumor spread). Since two decades, single-incision endoscopic surgery was introduced to the surgical community. ${ }^{2}$ Following the premise of causing the least damage to the abdominal wall, SPL surgery applied in the field of hepatic resection, has become an attractive procedure for many surgeons. It was first reported in 2010, performing a limited hepatic resection of a hepatocellular carcinoma (HCC). Since then, several papers have been published, describing the safety and feasibility of SPL liver surgery. ${ }^{6,7}$ In 2014, the first randomised prospective study comparing conventional multi-port laparoscopic hepatic surgery $(n=19)$ with SPL $(n=19)$ was published, without finding statistically significant differences in surgical time and intraoperative blood loss; but observing a shorter hospital stay in SPL patients (2.5 SD 1.7 days vs. 4.0 SD 2.1 days $p<0.05){ }^{8}$

SPL hepatic resection has shown to provide a series of advantages over multiport laparoscopic surgery, such as reduction of postoperative pain and the morbidity that involves the use of other ports, early recovery, in addition to the evident aesthetic benefit due to a small single incision. ${ }^{2,4}$ But several limitations have been described with these approaches, mainly related to size and location of liver lesions, but also with the technical difficulty of triangulation loss and limited movement range. ${ }^{6,7}$ 
Some groups contemplate that the history of previous abdominal surgeries is a contra-indication for this type of approach. ${ }^{8}$ In this work, that condition was the main reason to indicate SPL hepatic resection. Precisely, the advantage of SPL over conventional laparoscopy is even more pronounced in these cases, since the presence of adhesions due to previous surgeries increase the risk resulting from the insertion of several ports. Furthermore, the incision is larger than that required for the laparoscopic ports, which allows a better visualisation and a safer entrance to the abdominal cavity. In none of the 10 procedures were intraoperative complications related to the surgical technique, which coincided with other authors. ${ }^{6}$ After completing the hepatic resection, the authors proceeded to externalise the surgical specimen through the incision protected by the wall retractor Alexis ${ }^{\circledR}$, reducing the risk of wound infection and the possibility of spreading the disease on the abdominal wall.

At the study unit, GlovePort was used in all the cases. This glove technique was introduced in 2004 and has increased its popularity due to the numerous advantages it offers. ${ }^{9}$ The GlovePort provides a wider range of motion, supports the use of conventional straight pliers, admits the simultaneous use of 5 instruments without size restrictions, and it does not require modifying the size of the laparotomy for the sample extraction. ${ }^{10,11}$

Liver metastasis from colorectal cancer and HCC are the main indications to perform SPL hepatic resection; and both lesions have a high risk of recurrence. ${ }^{1,6}$ Due to this, there is a great possibility that these patients require repetitive liver resections during the follow-up. In the experience of the authors, performing a SPL resection, it offers a better view and a safer entrance to the abdominal cavity foreseeably, blocked by previous surgery adhesions.

\section{CONCLUSION}

Based on the reported experience, SPL hepatic surgery in patients with history of abdominal surgeries is a feasible technique and an alternative to take into account, compared to conventional laparoscopic surgery. This approach allows patients, with history of multiple abdominal surgeries, to take benefit from a minimally invasive technique, and at the same time, avoid the complications of a multiport laparoscopic surgery.

\section{ETHICAL APPROVAL:}

An Ethics Committee's approval was not necessary to carry out this manuscript.

\section{CONFLICT OF INTEREST:}

The authors declared no conflict of interest.

\section{AUTHORS' CONTRIBUTION:}

MCP: Data acquisition, analysis, design, interpretation.

JML: Critical revision, final approval.

CRRC: Data acquisition, design.

RNR: Data acquisition, analysis, design.

EASDR: Design and interpretation.

RFR: Critical revision, final approval.

\section{REFERENCES}

1. Fretland ÅA, Dagenborg VJ, Bjørnelv GMW, Kazaryan AM, Kristiansen R, Fagerland MW, et al. Laparoscopic versus open resection for colorectal liver metastases: The OSLO-COMET randomised controlled trial. Ann Surg 2018; 267(2):199-207. doi: 10.1097/SLA.0000000000002353.

2. Morales-Conde S, Peeters A, Meyer YM, Antoniou SA, Del Agua IA, Arezzo A, et al. European association for endoscopic surgery (EAES) consensus statement on single-incision endoscopic surgery. Surg Endosc 2019; 33(4): 996-1019. doi: 10.1007/s00464-019-06693-2.

3. Rao A, Rao G, Ahmed I. Laparoscopic left lateral liver resection should be a standard operation. Surg Endosc 2011; 25(5):1603-10. doi: 10.1007/s00464-010-1459-2.

4. Buell JF, Cherqui D, Geller DA, O'Rourke N, lannitti D, Dagher I, et al. The international position on laparoscopic liver surgery: The louisville statement, 2008. Ann Surg 2009; 250(5):825-30. doi: 10.1097/sla.0b013e3181b3b2d8.

5. Kobayashi S, Nagano H, Marubashi S, Wada H, Eguchi H, Takeda $Y$, et al. A single-incision laparoscopic hepatectomy for hepatocellular carcinoma: initial experience in a Japanese patient. Minim Invasive Ther Allied Technol 2010; 19(6):367-71. doi: 10.3109/13645706.2010.518731.

6. Aikawa M, Miyazwa M, Okamoto K, Toshimitsu Y, Okada K, Ueno Y. Single-port laparoscopic hepatectomy: Technique, safety and feasibility in a clinical case series. Surg Endosc 2011; 26(6):1696-1701. doi: 10.1007/s00464-011-2095-1.

7. Shetty GS, You YK, Choi HJ, Na GH, Hong TH, Kim DG. Extending the limitations of liver surgery: Outcomes of initial human experience in a high-volume center performing single-port laparoscopic liver resection for hepatocellular carcinoma. Surg Endosc 2012; 26(6):1602-1608. doi: 10.1007/s00464-011-2077-3.

8. Kim G, Lau AC, Chang SK. Single-incision laparoscopic hepatic resection in patients with previous hepatic resections: A mini case series. Asian J Endosc Surg 2014; 7(1):63-66. doi: 10.1111/ases.12072.

9. Ichihara T, Takada M, Fukumoto S, Yasuda T, Kuroda Y. A novel technique of finger-assisted laparoscopic surgery. Am J Surg 2004; 187(2):285-7. doi: 10.1016/j.amjsurg.2003. 11.003.

10. Gumbau V, Mir J. Glove port cholecystectomy. Cir Esp 2014; 92(5):363-4. doi: 10.1016/j.ciresp.2013.05.017.

11. Mir Labrador J, Gumbrau Puchol V. Glove port 2-3 segmentectomy. Cir Esp 2014; 92(8):562-63. doi: 10.1016/j.ciresp.2013.11.012. 